\title{
Geofractionation of heavy metals and application of indices for pollution prediction in paddy field soil of Tumpat, Malaysia
}

\begin{abstract}
The present study investigates the concentration of $\mathrm{Pb}, \mathrm{Cd}, \mathrm{Ni}, \mathrm{Zn}$, and $\mathrm{Cu}$ in the paddy field soils collected from Tumpat, Kelantan. Soil samples were treated with sequential extraction to distinguish the anthropogenic and lithogenic origin of $\mathrm{Pb}, \mathrm{Cd}, \mathrm{Ni}, \mathrm{Zn}$, and $\mathrm{Cu}$. ELFE and oxidizable-organic fractions were detected as the lowest accumulation of $\mathrm{Pb}, \mathrm{Cd}, \mathrm{Ni}, \mathrm{Zn}$, and $\mathrm{Cu}$. Therefore, all the heavy metals examined were concentrated, particularly in resistant fraction, indicating that those heavy metals occurred and accumulated in an unavailable form. The utilization of agrochemical fertilizers and pesticides might not elevate the levels of heavy metals in the paddy field soils. In comparison, the enrichment factor and geoaccumulation index for $\mathrm{Pb}, \mathrm{Cd}, \mathrm{Ni}, \mathrm{Zn}$, and $\mathrm{Cu}$ suggest that these heavy metals have the potential to cause environmental risk, although they present abundance in resistant fraction. Therefore, a complete study should be conducted based on the paddy cycle, which in turn could provide a clear picture of heavy metals distribution in the paddy field soils.
\end{abstract}

Keyword: Enrichment factor; Geoaccumulation index; Heavy metals; Paddy field soil; Sequential extraction procedure. 